\title{
Cannabinoid Hyperemesis Syndrome: Rare or Underdiagnosed?
}

\author{
Selena Au MD, Ali Rezaie MD
}

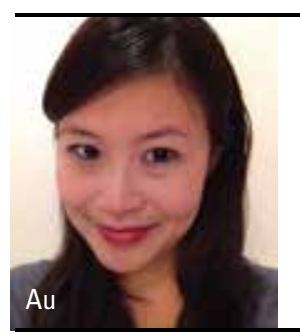

\begin{abstract}
About the Authors
Selena Au is a member of the Department of Critical Care Medicine at the Cumming School of Medicine in Calgary, Alberta and holds a Masters in Science in Quality Improvement and Patient Safety. Ali Rezaie is a gastroenterologist at Cedars Sinai Medical Center in Los Angeles. Correspondence may be directed to selena.au@albertahealthservices.ca.
\end{abstract}

\section{Case}

A 38-year-old male presented to the emergency department with severe acute-on-chronic abdominal pain. For the previous 20 years, he had experienced daily sharp epigastric pain with generalization to the entire abdomen. The pain typically began late in the morning and could last from hours to days. It was associated with nausea, vomiting, diaphoresis, and occasionally fever, diarrhea, and fatty or bloody bowel movements. These symptoms were not associated with food consumption. Over the previous five years, the patient had lost over $20 \mathrm{~kg}$ in weight and had noticed a marked decline in his performance at work and in the quality of his leisure time. He found symptom relief by smoking rolled marijuana cigarettes (“joints"), which he had been using three times per day since his teens. His pain crises were alleviated only with soaking in a tub of "scalding hot" bath water which he drew up ritualistically every morning.

The patient's symptoms had previously been investigated by his family physician, who suspected acute intermittent porphyria (AIP), but it is unclear what medical diagnostics had been performed. Quetiapine (50 mg qhs) had been prescribed and started one year prior to presentation, but during a review of systems, the patient denied having had any psychiatric symptoms. His medical history was significant only for smoking and lactose intolerance. Review of systems and family history were negative for autoimmune, infectious, malignant, or inflammatory bowel disease. When questioned as to why he chose to come to the emergency department just then, the patient replied that his family physician had suggested that he present during one of the more severe pain crises in order to allow laboratory work-up to confirm the diagnosis of AIP. At the time of presentation, the patient had been ill for the previous four days.
On examination, the patient was febrile $\left(38.6^{\circ} \mathrm{C}\right)$, hypertensive (195/113), and markedly dehydrated. He was of thin habitus and had normal results on cardiorespiratory examination. His abdomen was nondistended but diffusely tender. Abdominal rigidity with guarding was noted by the emergency physician but was absent on reassessment by internal medicine.

The patient's laboratory investigation results were consistent with a stress response and dehydration, including hemoglobin = $193 \mathrm{~g} / \mathrm{L}$, white blood cell count $=20 \times 109 \mathrm{~g} / \mathrm{L}$, creatinine $=164$ $\mu \mathrm{mol} / \mathrm{L}$, and lactate $=2.7 \mathrm{mmol} / \mathrm{L}$. Liver enzymes and the results of tests of hepatic synthesis were normal. Urine porphobilinogen at the time of crisis was negative for AIP.

Upon a review of the literature, a diagnosis of cannabinoid hyperemesis syndrome was made. To rule out other organic etiologies, the patient underwent abdominal computed tomography, which was unremarkable. Upper gastrointestinal endoscopy with gastric biopsies revealed no pathology.

\section{Discussion}

Cannabinoid hyperemesis syndrome (CHS) is a previously described but underdiagnosed adverse effect of marijuana use. It was first characterized in a group of nine patients by Australian investigators in 2004. Clinical features of the syndrome include the following:

1. long-term, excessive use of marijuana;

2. a cyclical vomiting pattern that often begins years after the initiation of substance use;

3. abdominal pain;

4. compulsive hot showering or bathing, with symptom relief; and

5. the resolution of symptoms upon cessation of marijuana use. ${ }^{1}$ 
Since this initial description, approximately 50 case reports and series have appeared internationally. The largest case series to date includes 98 patients reviewed at the Mayo Clinic from 2005 to 2010 and characterizes the typical features of patients with CHS. ${ }^{2}$ Common features of cases described in the literature include long-standing undiagnosed symptoms; multiple unnecessary diagnostic tests; and major surgical intervention for symptoms, with no relief. ${ }^{3}$ Table 1 lists the typical features of CHS patients in addition to the cardinal features listed above.

Clinical Presentation of a Patient with Cannabinoid Hyperemesis Syndrome ${ }^{3}$

\begin{tabular}{|l|l|}
\hline Essential for diagnosis & $\begin{array}{l}\text { Long-term cannabis use - Typical patients have } \\
\text { years of use, but cases after four months from } \\
\text { onset of marijuana use have been reported }\end{array}$ \\
\hline Major features & Severe cyclic nausea and vomiting \\
\hline & Abdominal pain, epigastric or periumbilical \\
\hline & Relief of symptoms with hot showers or baths \\
\hline & $\begin{array}{l}\text { Weekly use of marijuana - Majority of patients } \\
\text { are daily users }\end{array}$ \\
\hline & Resolution with cannabis cessation \\
\hline & Age less than 50 years old \\
\hline & Morning predominance of symptoms \\
\hline & Normal bowel habits \\
\hline & Weight loss of $>5 \mathrm{~kg}$ \\
\hline & $\begin{array}{l}\text { Autonomic features such as low-grade fever, } \\
\text { flushing, or diaphoresis }\end{array}$ \\
\hline
\end{tabular}

\section{Pathophysiology}

The pathophysiology of CHS remains poorly understood. Cannabinoids exert their psychoactive and antiemetic properties centrally on cannabinoid type 1 (CB1) receptors; cannabinoid type 2 (CB2) receptors are typically found peripherally in nonneuronal tissues. ${ }^{4}$ Disturbances of the hypothalamuspituitary-adrenal axis and the presence of autonomic instability have been described as the framework for symptoms in CHS. ${ }^{2}$ It has been postulated that the chronic stimulation of CB1 may cause receptor downregulation and internalization, leading to the paradoxical vomiting reaction. ${ }^{5} \mathrm{CB} 1$ receptors are also located on peripheral enteric nerves, where their stimulation is known to slow gastrointestinal transit, potentially overwhelming the antiemetic central CB1 effects.5 The behaviour of compulsive hot bathing and showering remains an area of much speculation but likely relates to the effect of cannabinoids on CB1 receptors in the temperature-regulating centres of the hypothalamus. ${ }^{5}$

\section{Treatment}

Long-term follow-up in the Mayo Clinic case series was poor due to the majority of its patients' being referred from abroad. ${ }^{2}$ However, of the 10 patients who had complete follow-up (10\%), 7 stopped using cannabis, and 6 of the $7(86 \%)$ noted a complete resolution of their symptoms. The only patient who did not notice any improvement had stopped consuming marijuana only one month previously. Because of the lipophilic nature and long half-life of cannabinoids, prolonged abstinence must be encouraged. Although typical antiemetics and analgesics seem to provide little relief from acute symptoms, successes with intravenous haloperidol, ${ }^{6}$ risperidone, ${ }^{7}$ and lorazepam ${ }^{8}$ have been described.

In our patient's case, he was given information on his diagnosis and was advised to abstain from marijuana use with concurrent down-titration of his quetiapine. A follow-up telephone call six months after diagnosis revealed that his pain had continued in the setting of ongoing marijuana use. Three months after diagnosis, he had presented to the emergency department again, at which point he was off quetiapine but back on marijuana. He had abstained for one month but resumed use because of the lack of rapid symptom improvement.

\section{Implications}

In September 2013, Statistics Canada reported that more Canadians experienced symptoms of cannabis abuse or dependence in their lifetime (6.8\%), compared with other drugs (4.0\%). ${ }^{9}$ Of Canadians, $1.3 \%$ met the criteria for cannabis abuse or dependence in the past year. ${ }^{9}$ While these statistics pertain to recreational marijuana use, 37,000 licensed medical marijuana users receive treatment for chemotherapy-induced nausea and vomiting and other conditions. ${ }^{10}$ This number is expected to reach 400,000 in the next decade. Effective April 1, 2014, Health Canada's new medical marijuana regulations shift the responsibility from federal regulators to doctors and nurse practitioners to write "medical documents" similar to prescriptions and authorizing patients to obtain marijuana from a federally licensed provider. ${ }^{11}$ As with any other safe prescribing practice, the physician must have an adequate understanding of adverse reactions and must disclose them to the patient. However, as demonstrated by our case, the literature on the adverse effects of chronic marijuana use is incomplete. Because the general public thinks of marijuana as having antiemetic properties, patients may not disclose their use of it during history taking unless specifically probed by a medical professional. Similarly, symptom relief by hot baths may be the tipoff for CHS, but only for a physician primed on this condition. 


\section{References}

1. Allen JH, de Moore GM, Heddle R, Twartz JC. Cannabinoid hyperemesis: cyclical hyperemesis in association with chronic cannabis abuse. Gut 2004;53:1566-70.

2. Simonetto DA, Oxentenko AS, Herman ML, Szostek JH. Cannabinoid hyperemesis: a case series of 98 patients. Mayo Clin Proc 2012;87:114-9.

3. Sofka S, Lerfald N. Cannabinoid hyperemesis syndrome: a case series. W V Med J 2013;109:20-3.

4. Chang YH, Windish DM. Cannabinoid hyperemesis relieved by compulsive bathing. Mayo Clin Proc 2009;84:76-8.

5. Hopkins CY, Gilchrist BL. A case of cannabinoid hyperemesis syndrome caused by synthetic cannabinoids. J Emerg Med 2013;45:544-6.

6. Hickey JL, Witsil JC, Mycyk MB. Haloperidol for treatment of cannabinoid hyperemesis syndrome. Am J Emerg Med 2013;31:1003.e5-6.

7. Roelofs J, Vorel SK, Vorel-Havelkova E, Brombacher PJ. [Cannabinoid hyperemesis with the unusual symptom of compulsive bathing.] Ned Tijdschr Geneeskd 2005;149:2376.

8. Cox B, Chhabra A, Adler M, et al. Cannabinoid hyperemesis syndrome: case report of a paradoxical reaction with heavy marijuana use. Case Rep Med 2012;2012:757696.

9. Pearson C, Janz T, Ali J. Mental and substance use disorders in Canada. Statistics Canada catalogue no. 82-624-X. Ottawa: Statistics Canada, 2013 Sept [cited 2013 Nov]; http://www.statcan.gc.ca/pub/82-624-x/2013001/ article/11855-eng.pdf.

10. Wingrove J. Patients, doctors upset by Canada's commercialization of marijuana. The Globe and Mail 2013 Oct 3 [cited 2013 Nov 13]; http://www. theglobeandmail.com/news/national/patients-doctors-upset-by-canadascommercialization-of-marijuana/article14693911/.

11. Health Canada. Ottawa: Health Canada, 2013 Jun 10 [cited 2013 Nov 13]; http://www.hc-sc.gc.ca/ahc-asc/media/nr-cp/_2013/2013-79-eng.php.

12. Sullivan S. Cannabinoid hyperemesis. Can J Gastroenterol 2010;24:284-5. 